\title{
Preemptive intravenous iron therapy
}

versus autologous whole blood therapy for early

postoperative hemoglobin level in patients

undergoing bimaxillary orthognathic surgery: a prospective randomized noninferiority trial

Min Suk Chae ${ }^{1}$, Mihyun Lee ${ }^{1}$, Min Ho Choi ${ }^{2}$, Je Uk Park ${ }^{2}$, Misun Park ${ }^{3}$, Young Hoon Kim ${ }^{1}$, Hoon Choi ${ }^{1}$, Jin Joo ${ }^{1}$ and Young Eun Moon ${ }^{1 *}$ (1)

\begin{abstract}
Background: Previous studies have reported the efficacy and safety of intravenous (IV) iron therapy during the perioperative period as an alternative and adjunct to allogeneic blood transfusion. Preemptive IV iron therapy provides noninferior hemoglobin levels on postoperative day (POD) 1 compared to autologous whole blood therapy (AWBT) in healthy patients who had undergone bimaxillary orthognathic surgery.

Methods: This was a prospective, patient-randomized, noninferiority trial. After excluding 2 patients, 64 patients were divided into two groups: the IV iron therapy group (patients received IV iron infusion 4 weeks before surgery; $n=32$ ) and the AWBT group ( 2 units of autologous whole blood were collected 4 and 2 weeks before surgery; $n=32$ ). The primary outcome was hemoglobin level on POD 1 and the prespecified noninferiority limit was $-1 \mathrm{~g} / \mathrm{dL}$.

Results: Baseline data were comparable, including hemoglobin and iron levels, between the two groups. Immediately before surgery, the levels of hemoglobin, iron, and ferritin were higher in the IV iron group than in the AWBT group. The mean treatment difference (iron group-whole blood group) in hemoglobin level on POD 1 between the two groups was $0.09(95 \% \mathrm{Cl}=-0.83$ to 1.0). As the lower limit of the $95 \% \mathrm{Cl}(-0.83)$ was higher than the prespecified noninferiority margin $(\delta=-1)$, noninferiority was established. On POD 2, the hemoglobin level became lower in the iron group, which eventually led to greater requirement of allogeneic blood transfusion compared to the whole blood group. However, the iron group did not require allogeneic blood transfusion during or early after surgery, and the whole blood group showed continuously higher incidence of overt iron deficiency compared to the iron group.

Conclusion: As collection of autologous whole blood caused overt iron loss and anemia before surgery and intraoperative transfusion of whole blood was not able to prevent the occurrence of persistent iron deficiency after surgery, IV iron therapy was found to have potential benefits for iron homeostasis and subsequent erythropoiesis in healthy patients early after bimaxillary orthognathic surgery.
\end{abstract}

\footnotetext{
*Correspondence: momo0910@catholic.ac.kr

${ }^{1}$ Department of Anesthesiology and Pain Medicine, Seoul St. Mary's

Hospital, College of Medicine, The Catholic University of Korea, 222,

Banpo-daero, Seocho-gu, Seoul 06591, Republic of Korea

Full list of author information is available at the end of the article
}

(C) The Author(s) 2021. Open Access This article is licensed under a Creative Commons Attribution 4.0 International License, which permits use, sharing, adaptation, distribution and reproduction in any medium or format, as long as you give appropriate credit to the original author(s) and the source, provide a link to the Creative Commons licence, and indicate if changes were made. The images or other third party material in this article are included in the article's Creative Commons licence, unless indicated otherwise in a credit line to the material. If material is not included in the article's Creative Commons licence and your intended use is not permitted by statutory regulation or exceeds the permitted use, you will need to obtain permission directly from the copyright holder. To view a copy of this licence, visit http://creativecommons.org/licenses/by/4.0/. The Creative Commons Public Domain Dedication waiver (http://creativeco mmons.org/publicdomain/zero/1.0/) applies to the data made available in this article, unless otherwise stated in a credit line to the data. 
Trial registration: Clinical Research Information Service, Republic of Korea, approval number: KCT0003680 on March 27, 2019. https://cris.nih.go.kr/cris/search/search_result_st01_kren.jsp?seq=15769\&sLeft=2\&ltype=my\&rtype=my.

Keywords: Anemia, Iron, Ferric carboxymaltose, Autologous whole blood, Bimaxillary orthognathic surgery

\section{Background}

Bimaxillary orthognathic surgery has been widely performed to correct bimaxillary prognathism or to reposition a mid-facial depression that is frequently associated with a higher risk for large-scale hemorrhage or transfusion requirement during surgery, because of the facial anatomy and surgical approach [1]. Strategies to decrease the use of allogeneic blood transfusion include preoperative autologous blood donation and intraoperative hypotensive anesthesia. Autologous whole blood therapy (AWBT) has been encouraged in healthy and young patients because of concerns about allogeneic blood transfusion-related complications, such as infection, allergic or anaphylactic reactions, and alloimmunization [2-4]. In surgeries where a large amount of blood loss is anticipated, such as cardiac or orthopedic surgery, intraoperative transfusion of autologous whole blood favorably enhances postoperative recovery after surgery, including reduced rates of respiratory failure, pneumonia, chest tube output, reoperation for bleeding or infection, and length of hospital stay $[5,6]$.

However, in whole blood donation studies [7, 8], donors have been reported to have lost large amounts of iron on harvesting of a unit of whole blood $(500 \mathrm{~mL}$, plus $25 \mathrm{~mL}$ for testing), and it requires more than 6 months to restore the iron to the level before donation with a standard diet. After regular blood donation, approximately $25-35 \%$ of blood donors become iron deficient, subsequently leading to side effects that can impact health, such as overt anemia, fatigue, neurocognitive changes, pica, and restless legs syndrome [6, $8-11]$. Low-dose oral iron intake was reported to contribute to marked reduction of hemoglobin recovery time after donation compared to no oral iron intake, but full recovery of iron and hemoglobin levels took a long time [8]. A previous retrospective study suggested that a larger proportion of patients who received intravenous (IV) ferric carboxymaltose, as a dextranfree IV iron complex, experienced effective reversal of acute isovolemic anemia compared to those without treatment [12]. Compared to oral iron, high-dose IV iron infusion is also associated with faster and higher replenishment of depleted hemoglobin and iron levels without adverse events [13]. Many surgical studies have suggested that IV iron therapy before or after surgery may be efficacious and safe as an alternative and adjunct to allogeneic blood transfusion [10, 14-17]. However, no studies have confirmed this observation in patients who have undergone bimaxillary orthognathic surgery.

We hypothesized that IV iron therapy would provide noninferior hemoglobin levels on postoperative day (POD) 1 compared to AWBT, while reducing postoperative adverse effects of iron depletion and less discomfort/ pain during treatment. Therefore, we conducted a randomized, noninferiority clinical trial on healthy patients who had undergone bimaxillary orthognathic surgery.

\section{Patients and methods}

\section{Ethical considerations}

This was a prospective, patient-randomized, noninferiority trial. The protocol was approved by the Institutional Review Board of Seoul St. Mary's Hospital Ethics Committee (approval no. KC18MESI0583) on December 19, 2018. The study was performed in accordance with the principles of the Declaration of Helsinki. The study protocol was prospectively registered at a publicly accessible clinical registration site that is recognized by the International Committee of Medical Journal Editors (Clinical Research Information Service, Republic of Korea, approval number: KCT0003680) on March 27, 2019. Written informed consent was obtained from all patients at our hospital who were enrolled between March 2019 and May 2020. The study adhered to the Consolidated Standards of Reporting Trials (CONSORT) guidelines (Additional file 1) and a CONSORT flow chart is provided in Fig. 1. Additional file 2 presents a summary of our study protocol.

\section{Inclusion and exclusion criteria}

The inclusion criteria for this study were as follows: age $\geq 20$ years; scheduled for elective bimaxillary orthognathic surgery; and American Society of Anesthesiologists (ASA) physical status I or II [18]. Exclusion criteria were as follows: hemodynamic instability requiring rescue therapy, such as strong vasopressor infusion (i.e., epinephrine or norepinephrine); ASA physical status III-V; history of iron drug-related side effects, such as allergy; medication history with anticoagulants, such as aspirin, clopidogrel, or warfarin; anemia (i.e., hemoglobin level $<11 \mathrm{~g} / \mathrm{dL})[19,20]$; and refusal to participate in the study. 


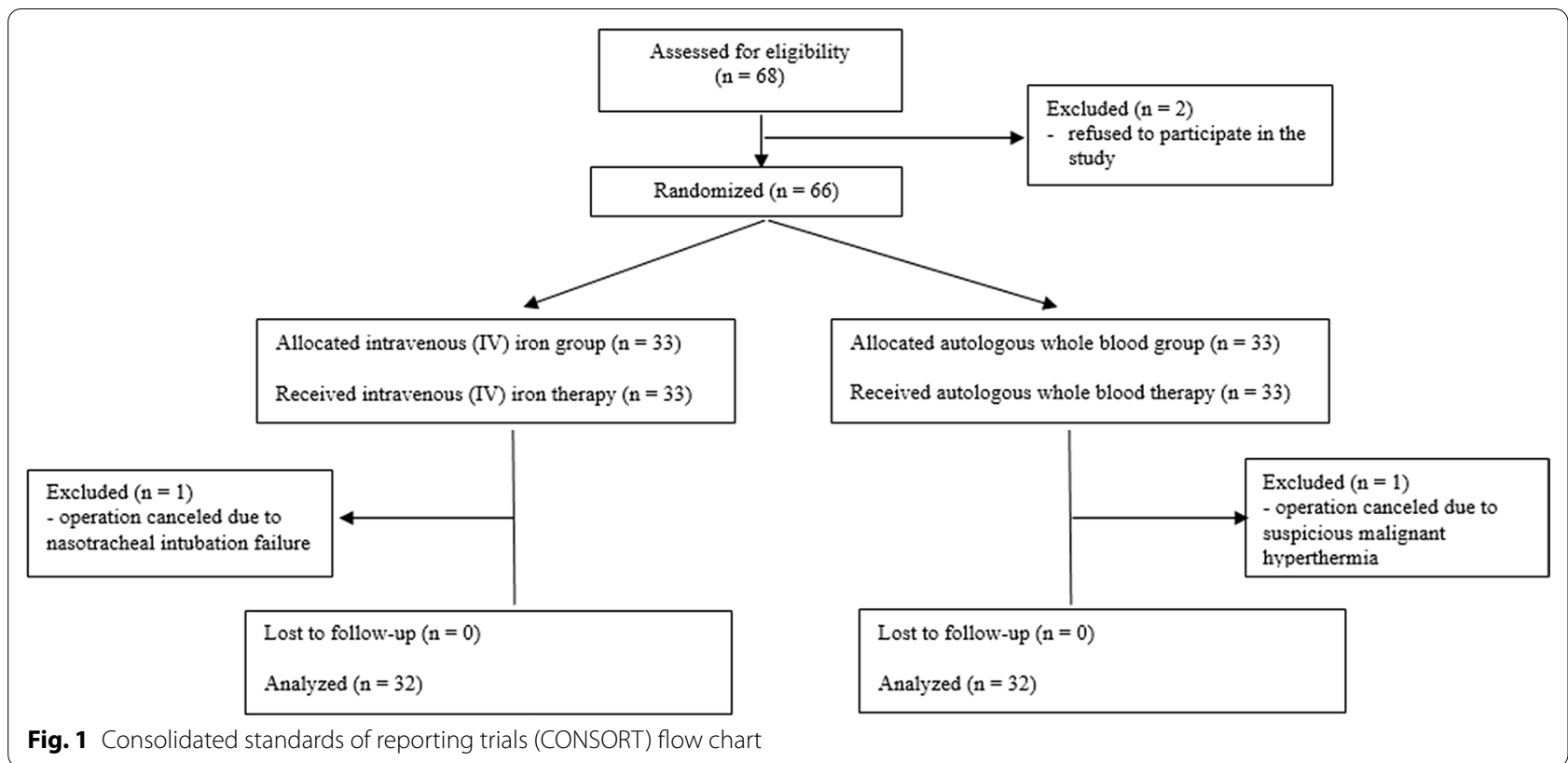

\section{Randomization}

The patients were randomly divided into two groups: the IV iron group and the AWBT group. Randomization was performed using sealed, opaque envelopes. An independent colleague randomly grouped the envelopes in blocks of 10 with a 1:1 ratio to produce an equal distribution across the whole study period. The envelopes were stacked and stored. When an enrolled patient arrived in the treatment area, the upper envelope was opened by the attending physicians who performed the treatments, i.e., IV iron infusion or collection of whole blood. In the operating room, the attending anesthesiologist and nurses were aware of the group allocations, but they were not involved in future patient care or data collection.

\section{Treatment}

In the iron group, IV $500 \mathrm{mg}$ ferric carboxymaltose (Ferinject; Vifor Pharma, Glattbrugg, Switzerland) mixed with $100 \mathrm{~mL}$ normal saline was administered for $30 \mathrm{~min}$ 4 weeks before surgery in accordance with the manufacturer's instructions.

In the AWBT group, two units of autologous blood were collected, 1 unit at a time with an interval of at least 2 weeks between collections; thus, each unit was collected on 4 and 2 weeks before surgery. The blood volume collected at one time was $320 \mathrm{~mL}$, and therefore, the total amount of whole blood was $640 \mathrm{~mL}$. It was stored in blood bags with a preservation solution of citrate-phosphate-dextrose-adenine at $4{ }^{\circ} \mathrm{C}$ until the day of surgery, which is a standard blood management of the hospital
[19-22]. All collected whole blood was transfused intraoperatively using a warming infusion device.

During and after IV iron supplementation or AWBT, all patients were closely monitored for complications, such as fever $\left(\geq 38^{\circ} \mathrm{C}\right)$, phlebitis, nausea/vomiting, injectionsite reactions (i.e., pain or urticaria), dizziness/syncope, hypotension (i.e., $\mathrm{SBP}<90 \mathrm{mmHg}$ ), tachycardia (i.e., heart rate $[\mathrm{HR}]>100$ beats/min) or hypersensitivity/ allergy.

\section{Surgery and anesthesia}

Surgical technique and anesthetic care were as described previously [23]. Briefly, the care of patients was standardized between both groups apart from the treatments applied. Bimaxillary orthognathic surgery, including a bilateral sagittal split osteotomy and a Le Fort I osteotomy, was performed by an experienced surgeon, and balanced general anesthesia was provided without premedication by experienced attending anesthesiologists. To reduce surgical bleeding, induced hypotensive anesthesia with a systolic blood pressure (SBP) $<100 \mathrm{mmHg}$ was achieved by intermittent IV boluses of sodium nitroprusside or nicardipine, especially between the beginning of osteotomy and the end of osteosynthesis. Hemodynamic monitoring, including SBP, diastolic blood pressure (DBP), HR, electrocardiogram, pulse oximetry, and end-tidal carbon dioxide pressure, were regularly recorded every 5 min during surgery. Blood lost by surgical hemorrhage was replaced to prevent hypovolemia with one bag $(500 \mathrm{~mL})$ of colloid product $(6 \%$ 
hydroxyethyl starch, volulyte) in the IV iron group and by 2 units $(640 \mathrm{~mL})$ of autologous whole blood in the AWBT group.

Based on the practice guideline [19], allogeneic packed red blood cell (PRBC) transfusion was performed at the discretion of the attending anesthesiologists or physicians, when hemoglobin level reached between 6 and $10 \mathrm{~g} / \mathrm{dL}$ with consideration of potential or actual ongoing hemorrhage, intravascular volume status, organ ischemic signs, or adequacy of cardiopulmonary reserve. These blood products were administered unit-by-unit.

\section{Clinical variables}

Preoperative findings included demographic variables, ASA physical status, vital signs (i.e., SBP, DBP, and HR). Intraoperative findings included total operation duration, average vital signs during surgery, total amount of fluid input, including crystalloid and colloid, hemorrhage, and urine output. Laboratory variables (i.e., hemoglobin, hematocrit, red blood cell [RBC] count, mean corpuscular volume, mean corpuscular hemoglobin, mean corpuscular hemoglobin concentration, iron, ferritin, C-reactive protein, white blood cell count, neutrophil, lymphocyte, and platelet counts, international normalized ratio [INR], activated partial thrombin time, antithrombin III, and fibrinogen) were regularly measured four times: 4 weeks before surgery (baseline), immediately before surgery, and on PODs 1 and 2.

\section{Outcomes}

The primary outcome was the hemoglobin level on POD 1. The secondary outcomes included the levels of inflammatory and coagulation variables on PODs 1 and 2 , and changes in blood cell-related variables during POD 2. The incidences of anemia defined as hemoglobin level $<13 \mathrm{~g} / \mathrm{dL}$ in males and $<12 \mathrm{~g} / \mathrm{dL}$ in females, low iron level defined as $<50 \mu \mathrm{g} / \mathrm{L}$, and low ferritin level defined as $<15 \mathrm{ng} / \mathrm{mL}$ in males and $<10 \mathrm{ng} / \mathrm{mL}$ in females were analyzed in the two groups $[9,19]$. The degree of discomfort when iron was intravenously infused or whole blood was collected was analyzed using a visual analog scale (VAS; $0=$ no discomfort and $10=$ the worst discomfort). Surgical complications, such as allogeneic blood transfusion, were analyzed using Clavien-Dindo classification [24], and total hospital stay was measured in both groups.

\section{Statistical analyses}

The sample size was calculated based on the primary endpoint according to the noninferiority hypothesis. The predetermined noninferiority limit $(\delta)$ was set to a difference in hemoglobin level of $-1 \mathrm{~g} / \mathrm{dL}$ between the two groups (IV iron group-AWBT group) that was considered clinically acceptable by experts at our institution.
Based on preliminary data, a standard deviation (SD) of $1.3 \mathrm{~g} / \mathrm{dL}$ was assumed for the hemoglobin distribution. With $\alpha=0.05$ and power of $90 \%, 30$ patients were required in each group. Assuming a 10\% dropout rate, we decided to enroll 33 patients per group. For the primary outcome, the noninferiority of the IV iron therapy was considered if the lower boundary of the two-sided 95\% confidence interval $(\mathrm{CI})$ lay above the noninferiority margin of $-1 \mathrm{~g} / \mathrm{dL}$ [25].

Values are expressed as the mean $\pm \mathrm{SD}$, median with interquartile range (IQR), or as numbers with percentages. The normality of the distribution of the continuous data was evaluated using the Shapiro-Wilk test. The perioperative findings were compared between the two groups using the unpaired $t$ test or the Mann-Whitney $U$ test, and Pearson's $\chi^{2}$ test or Fisher's exact test, as appropriate. Serial changes in RBC-related variables were analyzed using the paired $t$ test or Wilcoxon's signed rank test. All tests were two-sided, and $p<0.05$ was taken to indicate statistical significance. Statistical analyses were performed using SPSS for Windows (ver. 24.0; IBM Corporation, Armonk, NY) and MedCalc for Windows software (ver. 11.0; MedCalc Software, Ostend, Belgium).

\section{Results}

A total of 68 patients were assessed for eligibility and enrolled in this study. However, two patients refused to participate $(n=2)$. In addition, one patient with suspected malignant hyperthermia $(n=1)$, and one patient in whom nasotracheal intubation failed $(n=1)$, were excluded. Therefore, 64 patients were included in the analyses (Fig. 1). Our study population included healthy patients without comorbidities, such as hypertension, diabetes mellitus, and anemia. There were no adverse events related to IV iron therapy or AWBT, such as fever $\left(\geq 38{ }^{\circ} \mathrm{C}\right)$, phlebitis, nausea/vomiting, injection-site reactions (i.e., pain or urticaria), dizziness/syncope, hypotension, tachycardia, or hypersensitivity/allergy, before surgery. There were no significant differences in preoperative and intraoperative findings between the two groups (Table 1).

\section{Comparison of perioperative red blood cell-related findings between the two groups}

Four weeks before surgery (baseline) (Table 2), hemoglobin, hematocrit, RBC count, red cell index (i.e., $\mathrm{MCV}$, $\mathrm{MCH}, \mathrm{MCHC}$ ), iron, and ferritin were comparable between the two groups. Immediately before surgery, the $\mathrm{RBC}$ count, hemoglobin, hematocrit, iron, and ferritin levels were higher in the IV iron group than the AWBT group. On POD 1, the levels of iron and ferritin were higher in the IV iron group than the AWBT group. On POD 2, the IV iron group showed lower hemoglobin level 
Table 1 Comparisons of pre- and intraoperative findings between the two groups

\begin{tabular}{|c|c|c|c|}
\hline Group & Intravenous iron & Autologous whole blood & $p$ \\
\hline $\mathbf{n}$ & 32 & 32 & \\
\hline \multicolumn{4}{|l|}{ Preoperative findings } \\
\hline Sex (male) & $16(50 \%)$ & $17(53 \%)$ & 0.802 \\
\hline Age (years) & $21(20-25)$ & $21(20-24)$ & 0.47 \\
\hline Height $(\mathrm{cm})$ & $170.0(160.7-176.8)$ & $169.5(164.0-177.0)$ & 0.527 \\
\hline Weight (kg) & $60.5(54.0-71.8)$ & $63.0(50.0-77.0)$ & 0.591 \\
\hline Body mass index $\left(\mathrm{kg} / \mathrm{m}^{2}\right)$ & $22.0 \pm 3.9$ & $22.6 \pm 5.3$ & 0.579 \\
\hline ASA physical status I & $32(100 \%)$ & $32(100 \%)$ & - \\
\hline \multicolumn{4}{|l|}{ Vital signs } \\
\hline Systolic blood pressure (mmHg) & $116 \pm 9$ & $118 \pm 13$ & 0.325 \\
\hline Diastolic blood pressure $(\mathrm{mmHg})$ & $72 \pm 10$ & $71 \pm 9$ & 0.664 \\
\hline Heart rate (beats/min) & $81 \pm 12$ & $81 \pm 12$ & 0.96 \\
\hline \multicolumn{4}{|l|}{ Intraoperative findings } \\
\hline Total operation duration (min) & $213 \pm 39$ & $230 \pm 35$ & 0.07 \\
\hline \multicolumn{4}{|l|}{ Average during surgery } \\
\hline Systolic blood pressure (mmHg) & $94(90-97)$ & $93(88-99)$ & 0.851 \\
\hline Diastolic blood pressure $(\mathrm{mmHg})$ & $52(46-55)$ & $53(48-59)$ & 0.371 \\
\hline Heart rate (beats/min) & $79(72-90)$ & $78(77-91)$ & 0.51 \\
\hline \multicolumn{4}{|l|}{ Total amount of fluid input ( $\mathrm{mL}$ ) } \\
\hline Crystalloid (mL) & $1250(1000-1975)$ & $1500(645-2250)$ & 0.968 \\
\hline Colloid (mL) & $650(500-750)$ & - & - \\
\hline Autologous whole blood (mL) & - & $640(640-640)$ & - \\
\hline Hemorrhage (mL) & $900(500-1138)$ & $1000(700-1425)$ & 0.424 \\
\hline Urine output (mL) & $150(120-250)$ & $215(50-400)$ & 0.491 \\
\hline
\end{tabular}

Values are expressed as mean $\pm S D$, median (interquartile) and number (proportion)

ASA American Society of Anesthesiologist

but higher levels of iron and ferritin compared to the AWBT group. Based on the values at 4 weeks before surgery, the levels of hemoglobin, hematocrit, and iron and RBC count decreased gradually during and early after surgery in both groups; however, the ferritin levels were continuously higher in the IV iron group than the AWBT group.

The incidence of anemia immediately before surgery was lower in the IV iron group than the AWBT group (Fig. 2). The incidences of low iron level immediately before surgery and on PODs 1 and 2 were lower in the iron group than the AWBT group. The incidence of low ferritin level immediately before surgery was lower in the iron group than the AWBT group.

Based on the values at 4 weeks before surgery (baseline), changes in hemoglobin levels immediately before surgery were lower, but these changes on POD 2 were higher in the IV iron group than the AWBT group (Table 3). The change in iron level on POD 1 was lower in the iron group than the AWBT group. Changes in ferritin levels immediately before surgery and on PODs 1 and 2 were higher in the iron group than the AWBT group.
Noninferiority of differences in hemoglobin levels before, during, and after surgery between the two groups

The mean treatment difference (IV iron group-AWBT group) in the hemoglobin level on POD 1 between the two groups was 0.09 (95\% $\mathrm{CI}=-0.83$ to 1.0$)$ (Fig. 3). As the lower limit of the $95 \% \mathrm{CI}(-0.83)$ was higher than the prespecified noninferiority margin $(\delta=-1)$, noninferiority was established. In addition, the mean treatment differences in hemoglobin levels between the two groups were as follows: immediately before surgery, 1.59 (95\% $\mathrm{CI}=0.73$ to 2.44$)$; and on POD $2,-0.81(95 \% \mathrm{CI}=-1.55$ to -0.06$)$.

\section{Comparison of other postoperative findings between the two groups}

The inflammatory findings before, during, and after surgery were comparable between the two groups (Additional file 3). With regard to coagulation findings, the platelet, antithrombin III, and fibrinogen levels on POD 1 were higher and the INR was more prolonged in the IV iron group than the AWBT group. On POD 2, the platelet and antithrombin III levels were lower and the 
Table 2 Comparisons of perioperative red blood cell related findings between the two groups

\begin{tabular}{|c|c|c|c|}
\hline Group & Intravenous iron & Autologous whole blood & $p$ \\
\hline $\mathrm{n}$ & 32 & 32 & \\
\hline \multicolumn{4}{|c|}{ Four weeks before surgery (baseline) } \\
\hline Hemoglobin (g/dL) & $14.5 \pm 1.4$ & $14.3 \pm 1.4$ & 0.529 \\
\hline Hematocrit (\%) & $42.8 \pm 3.8$ & $42.5 \pm 3.6$ & 0.79 \\
\hline RBC count $\left(\times 10^{12} / \mathrm{L}\right)$ & $4.8 \pm 0.4$ & $4.7 \pm 0.4$ & 0.491 \\
\hline \multicolumn{4}{|l|}{ Red cell index } \\
\hline $\mathrm{MCV}(\mathrm{fL})$ & $89.2 \pm 3.5$ & $89.3 \pm 2.3$ & 0.831 \\
\hline $\mathrm{MCH}(\mathrm{pg})$ & $30.1 \pm 1.3$ & $30.1 \pm 1.0$ & 0.991 \\
\hline $\mathrm{MCHC}(\%)$ & $33.9 \pm 0.9$ & $33.5 \pm 0.7$ & 0.09 \\
\hline Iron $(\mu \mathrm{g} / \mathrm{dL})$ & $128.9 \pm 48.6$ & $113.3 \pm 42.4$ & 0.176 \\
\hline Ferritin (ng/mL) & $105.7 \pm 92.9$ & $107.5 \pm 77.7$ & 0.932 \\
\hline \multicolumn{4}{|c|}{ Immediately before surgery } \\
\hline Hemoglobin (g/dL) & $13.5 \pm 1.4^{* * *}$ & $12.0 \pm 2.0^{* * *}$ & $<0.001$ \\
\hline Hematocrit (\%) & $40.2 \pm 2.7^{* * *}$ & $35.5 \pm 5.5^{* * *}$ & $<0.001$ \\
\hline RBC count $\left(\times 10^{12} / \mathrm{L}\right)$ & $4.5 \pm 0.4^{* * *}$ & $4.0 \pm 0.6^{* * *}$ & $<0.001$ \\
\hline \multicolumn{4}{|l|}{ Red cell index } \\
\hline $\mathrm{MCV}(\mathrm{fL})$ & $89.5 \pm 3.4$ & $89.1 \pm 3.7$ & 0.617 \\
\hline MCH (pg) & $30.1 \pm 1.3$ & $30.0 \pm 1.4$ & 0.631 \\
\hline MCHC (\%) & $33.8 \pm 0.8$ & $33.6 \pm 0.7$ & 0.401 \\
\hline Iron $(\mu \mathrm{g} / \mathrm{dL})$ & $98.6 \pm 33.0^{* * *}$ & $62.2 \pm 40.9^{* * *}$ & $<0.001$ \\
\hline Ferritin (ng/mL) & $271.2 \pm 156.4^{* *}$ & $66.3 \pm 111.6$ & $<0.001$ \\
\hline \multicolumn{4}{|l|}{ Postoperative day 1} \\
\hline Hemoglobin (g/dL) & $10.1 \pm 1.9^{* * *}$ & $10.1 \pm 1.8^{* * *}$ & 0.849 \\
\hline Hematocrit (\%) & $30.1 \pm 5.5^{* * *}$ & $29.7 \pm 4.9^{* * *}$ & 0.765 \\
\hline RBC count $\left(\times 10^{12} / \mathrm{L}\right)$ & $3.4 \pm 0.6^{* * *}$ & $3.4 \pm 0.6^{* * *}$ & 0.697 \\
\hline \multicolumn{4}{|l|}{ Red cell index } \\
\hline $\mathrm{MCV}(\mathrm{fL})$ & $89.0 \pm 1.7$ & $89.4 \pm 3.3$ & 0.542 \\
\hline $\mathrm{MCH}(\mathrm{pg})$ & $30.0 \pm 0.7$ & $30.0 \pm 1.2$ & 0.829 \\
\hline $\mathrm{MCHC}(\%)$ & $33.7 \pm 0.7$ & $33.7 \pm 0.8$ & 0.961 \\
\hline Iron $(\mu \mathrm{g} / \mathrm{dL})$ & $40.6 \pm 29.8^{* * *}$ & $22.7 \pm 12.1^{* * *}$ & 0.002 \\
\hline Ferritin (ng/mL) & $265.2 \pm 161.1^{* * *}$ & $102.3 \pm 96.2$ & $<0.001$ \\
\hline \multicolumn{4}{|l|}{ Postoperative day 2} \\
\hline Hemoglobin (g/dL) & $9.1 \pm 1.6^{* * *}$ & $9.9 \pm 1.4^{* * *}$ & 0.035 \\
\hline Hematocrit (\%) & $26.9 \pm 4.9^{* * *}$ & $29.4 \pm 4.3^{* * *}$ & 0.036 \\
\hline $\mathrm{RBC}$ count $\left(\times 10^{12} / \mathrm{L}\right)$ & $3.0 \pm 0.6^{* * *}$ & $3.3 \pm 0.5^{* * *}$ & 0.022 \\
\hline \multicolumn{4}{|l|}{ Red cell index } \\
\hline$M C V(f L)$ & $89.8 \pm 2.5$ & $89.9 \pm 3.5$ & 0.823 \\
\hline MCH (pg) & $30.4 \pm 1.0$ & $29.9 \pm 1.3$ & 0.081 \\
\hline MCHC (\%) & $33.9 \pm 0.5$ & $33.7 \pm 0.7$ & 0.433 \\
\hline Iron ( $\mu \mathrm{g} / \mathrm{dL})$ & $63.0 \pm 26.4^{* * *}$ & $41.4 \pm 22.9^{* * *}$ & 0.001 \\
\hline Ferritin (ng/mL) & $281.8 \pm 150.3^{* * *}$ & $107.3 \pm 93.5$ & $<0.001$ \\
\hline
\end{tabular}

Values are expressed as mean $\pm S D$ and number (proportion)

$R B C$ red blood cell, $M C V$ mean corpuscular volume, $M C H$ mean corpuscular hemoglobin, $H C H C$ mean corpuscular hemoglobin concentration

* $p<0.05$ based on the level at 4 weeks before surgery (baseline)

** $p<0.01$ based on the level at 4 weeks before surgery (baseline)

*** $p<0.001$ based on the level at 4 weeks before surgery (baseline) 


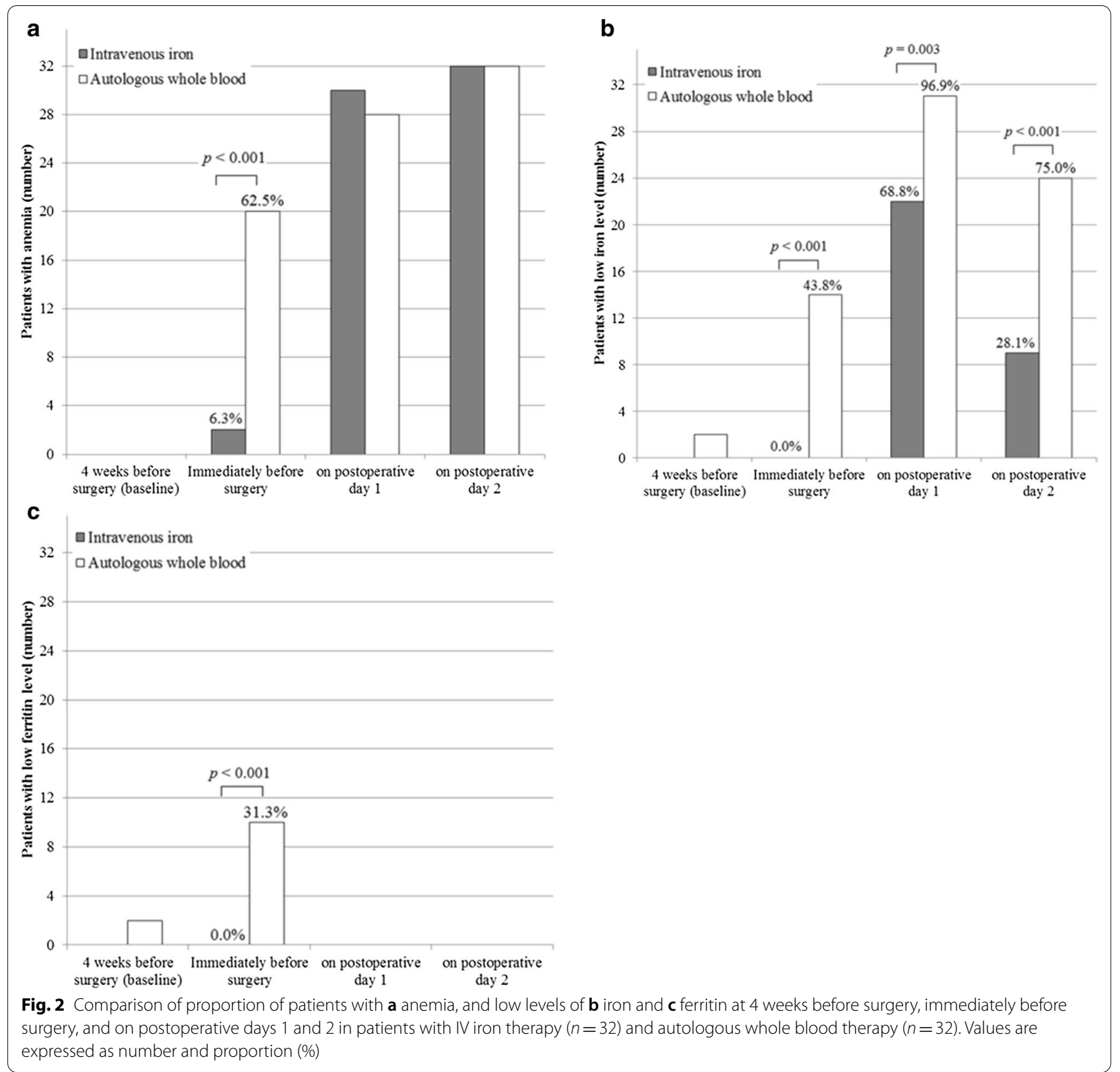

INR were more prolonged in the IV iron group than the AWBT group. However, postoperative coagulation values were within the respective normal ranges in both groups $[19,26]$.

Although all patients experienced a mild degree $(\leq 3$ VAS) of discomfort or pain in both treatment groups, the median (IQR) VAS was lower in the IV iron group than the AWBT group (0 [0-0] vs. 2 [], respectively; $p<0.001)$. The proportion of patients with ClavienDindo classification II related to requirement of allogeneic PRBC transfusion on POD 2 was higher in the IV iron group than the AWBT group $(n=8,25.0 \%$ vs. $n=1$,
$3.1 \%$, respectively; $p=0.026$ ). However, the total length of hospital stay was comparable between the two groups ( $2.5 \pm 0.6$ vs. $2.4 \pm 0.5$ days, respectively; $p=0.269$ ).

\section{Discussion}

We found that IV iron therapy provided noninferior hemoglobin levels compared to AWBT after bimaxillary orthognathic surgery in the first $24 \mathrm{~h}$ postoperatively. In the operating room, the patients with IV iron therapy showed higher levels of hemoglobin, iron, and ferritin than those with AWBT and they did not require allogeneic blood transfusion during surgery. In addition, the 
Table 3 Comparison of perioperative changes in hemoglobin, iron, and ferritin levels based on the values at 4 weeks before surgery (baseline) between the two groups

\begin{tabular}{lccc}
\hline $\begin{array}{l}\text { Group } \\
\mathbf{n}\end{array}$ & $\begin{array}{l}\text { Intravenous iron } \\
\mathbf{3 2}\end{array}$ & $\begin{array}{l}\text { Autologous whole blood } \\
\mathbf{3 2}\end{array}$ \\
\hline $\begin{array}{l}\text { Change of hemoglobin level (\%) } \\
\text { Immediately before surgery }\end{array}$ & $-6.47 \pm 5.51$ & $-16.36 \pm 10.27$ & $\mathbf{p}$ \\
Postoperative day 1 & $-29.92 \pm 11.21$ & $-29.73 \pm 8.38$ & $-30.64 \pm 7.02$ \\
$\quad$ Postoperative day 2 & $-37.18 \pm 10.07$ & & 0.938 \\
Change of iron level (\%) & & $-35.95 \pm 54.82$ & 0.004 \\
Immediately before surgery & $-14.78 \pm 39.97$ & $-76.26 \pm 15.57$ & $-56.27 \pm 35.9$ \\
Postoperative day 1 & $-65.9 \pm 23.04$ & & 0.082 \\
Postoperative day 2 & $-43.57 \pm 33.42$ & $-20.53 \pm 213.09$ \\
Change of ferritin level (\%) & & $45.38 \pm 195.97$ & 0.04 \\
Immediately before surgery & $273.28 \pm 324.54$ & $53.55 \pm 188.3$ & 0.148 \\
Postoperative day 1 & $261.35 \pm 281.57$ & 0.001 \\
Postoperative day 2 & $309.07 \pm 344.98$ & 0.001 \\
\hline
\end{tabular}

Values are expressed as mean $\pm S D$

Changes (\%) are defined as ((each value - value at 4 weeks before surgery)/value at 4 weeks before surgery) $\times 100$

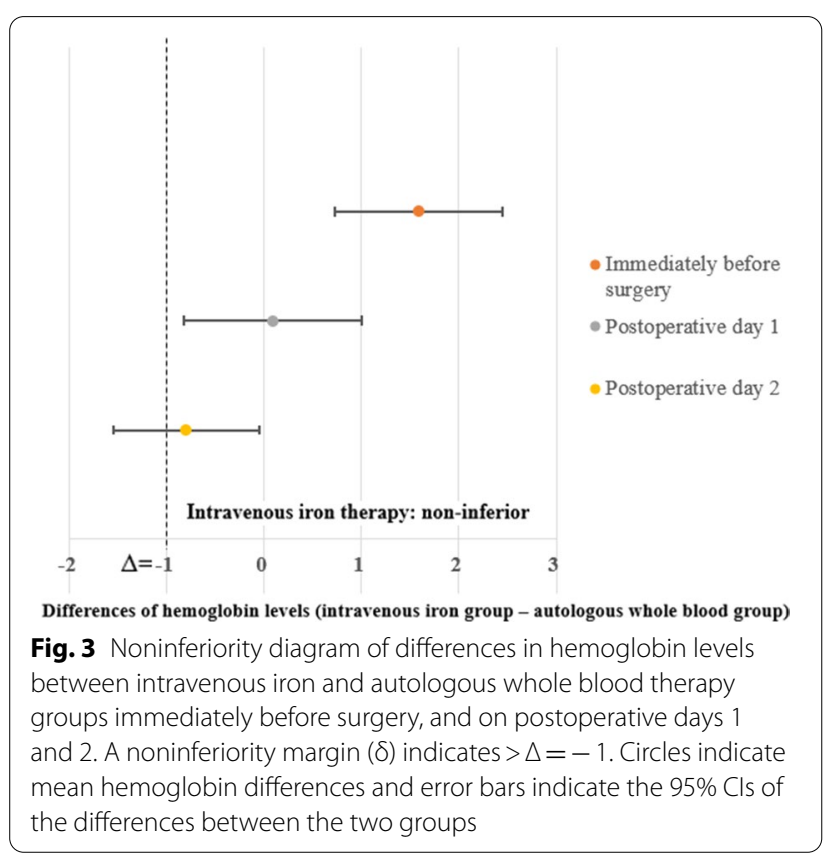

patients with IV iron infusion showed less discomfort/ pain during the treatment compared to those from whom whole blood was harvested. However, the hemoglobin level in the IV iron group decreased markedly thereafter, and on the second day after surgery led to a greater need for blood transfusion.

Many observational studies have suggested benefits of early IV iron therapy that lead to regaining oxygen carrying capacity and improvement of organ functional recovery and quality of life in critically ill patients, such as those with kidney or heart failure [15, 16, 27]. Hemorrhage is one of the most common complications during surgery that causes acute loss of oxygen delivery capability and components, such as hemoglobin and iron. These losses are markedly aggravated when lost blood is replaced with fluid, and eventually have a negative impact on short- and long-term prognostic outcomes. In patients at risk for iron storage shortage or overt anemia, early IV iron therapy helps build up the levels of hemoglobin and iron preoperatively and reduce the need for blood transfusion intraoperatively $[28,29]$. Piednoir et al. [10] reported that patients with iron deficiency but without anemia are associated with larger PRBC transfusions and poorer physical fatigue scores than those without iron deficiency or anemia after cardiac surgery. In Kim et al. [30], patients who received $500 \mathrm{mg}$ or $1000 \mathrm{mg}$ IV ferric carboxymaltose (ferric carboxymaltose group) had a better hemoglobin response, as determined by a hemoglobin increase $\geq 2 \mathrm{~g} / \mathrm{dL}$ from baseline, and greater improvements in iron-related variables (i.e., serum levels of ferritin and levels of transferrin saturation) 12 weeks after gastrectomy than patients who received IV normal saline (placebo group). The requirement of alternative anemia care, including oral iron or transfusion, was lower in the ferric carboxymaltose group than in the placebo group. In addition, the occurrence and aggravation of anemia were affected by active and persistent inflammatory response related to conditions of absolute and/or functional iron deficiency after surgery. As these conditions of iron deficiency were hardly corrected by the administration of oral iron due to a decrease in gastrointestinal iron absorption related to surgical stimuli, 
IV iron administration seemed to be an efficient and safe means of enhancing recovery from anemia and attenuating the requirement for allogeneic blood transfusion with very few severe side effects, such as drug allergy [17]. In a study of anemic critically ill patients, Iperen et al. [31] suggested that the regime with IV iron sucrose at dose of $20 \mathrm{mg} /$ day improved systemic inflammatory response with reduction in C-reactive protein level, and contributed to lowering both the requirement for blood transfusion and mortality rate.

However, commonly reported adverse events, associated with IV ferric carboxymaltose include injection site reactions, phlebitis, fever, nausea, constipation, headache, and diarrhea; reactions are mild to moderate in severity. In a large multicenter trial, the reported ferric carboxymaltose-related complications were injection site reactions $(2.3 \%)$ and urticaria $(2.3 \%)$, but there were no serious complications, such as hypersensitivity or anaphylactic reactions [30]. Among patients with chronic kidney dysfunction who received a higher dose of IV ferric carboxymaltose, two showed mild hypersensitivity that did not require hospitalization [32]. In women with a history of heavy uterine bleeding, an unexpected side-effect-hypophosphatemia-was reported, but no patients were symptomatic. Although this side-effect is not fully understood, it may be related to an increase in the phosphaturic hormone fibroblast growth factor- 23 [33]. Although previous studies and our results demonstrate the safety of IV ferric carboxymaltose, there are still theoretical mechanisms by which IV iron could exacerbate cardiovascular injury due to its effect on oxidative stress, and potential concerns related to IV iron worsening infections and hypersensitivity [19, 32-34].

In contrast to previous studies, our findings did not show positive postoperative results of IV iron therapy, which may be explained by differences in patient condition and surgical settings. In many studies that have reported favorable outcomes of IV iron therapy, the patients were anemic or iron-deficient before surgery, with chronic and critical illnesses, such as malignancy, and older age. These factors disturbed iron balance and decreased oxygen delivery capability of hemoglobin. The correction of iron deficiency by IV iron infusion facilitated the recovery of iron-containing oxygen transport carriers, such as suitable structure and concentration of hemoglobin [10, 14-16, 28-30]. However, our patients were healthy, young, and did not have any comorbidities or abnormal laboratory variables preoperatively. Prophylactic IV iron treatment in these patients may not be as effective as in patients with existing iron-deficient anemia. In Oh et al. [35], the incidence of allogeneic blood transfusion was significantly lower in patients who received preoperatively collected autologous blood than in patients who did not. This difference was predominantly greater in patients with a preoperative hemoglobin level $<14 \mathrm{~g} / \mathrm{dL}$ than $\geq 14 \mathrm{~g} / \mathrm{dL}$. However, the rate of discarding collected autologous blood was as high as $38.5 \%$ in patients with preoperative hemoglobin level $\geq 14 \mathrm{~g} / \mathrm{dL}$ compared to the rate of $10.5 \%$ in those with a level $<14 \mathrm{~g} /$ $\mathrm{dL}(p<0.0001)$. Therefore, appropriately raising the level of hemoglobin before surgery seems to be the cornerstone to successfully reducing the need for blood transfusion and the collection of large amounts of the patient's own whole blood [30, 36, 37]. However, immediate recovery of hemoglobin level after surgery is not possible with IV iron administration, because production and maturation of hemoglobin derived from stored iron, such as ferritin, require several weeks to months [38]. Therefore, although patients who received AWBT had a higher incidence of anemia and lower levels of iron and ferritin before and during surgery than patients with IV iron therapy, the active response to regain hemoglobin level after intraoperative hemorrhage may be better in such patients.

The AWBT is a technique in which the patient's own blood is collected and saved for a period of time before surgery, and reinfused during surgery. Repeated blood donations before surgery induce bone marrow cell proliferation and erythrocyte regeneration, which that accelerates hematopoietic function and postoperative recovery. These changes may decrease the requirement for allogeneic blood transfusion related to immunoreaction and infectious vulnerability $[5,39,40]$. However, the period from the first emergence of erythroid progenitor cells in the bone marrow to the emergence of mature erythrocytes in the peripheral blood is up to 4 weeks long, and erythrocyte regeneration in one withdrawn red blood cell unit takes up to 6 months [7-9]. Additionally, because of the limitations of conventional blood storage techniques using citrate-phosphate-dextrose-adenine solution for blood preservation and the red cell storage-life of 35 days at $4{ }^{\circ} \mathrm{C}$, the AWBT should commence $4-5$ weeks prior to surgery, allowing the collection of whole blood, and the last donation should take place at least $48-72 \mathrm{~h}$ before surgery to allow for equilibration of blood volume [21, $41,42]$. In patients who received the AWBT, the hematocrit and iron-related components significantly decreased from the initial level before AWBT to the level immediately before surgery [9]. Therefore, the AWBT is suitable primarily for young and robust patients without anemia scheduled for elective surgery in 4-5 weeks. 
This study had some limitations. First, although IV iron infusion was performed 4 weeks before surgery, $\mathrm{RBC}$ synthesis may not function sufficiently during this period. Further studies are required to investigate the optimal interval between IV iron therapy and surgery in patients without overt anemia scheduled for surgery. Second, we were not able to determine the optimal dose of IV iron for prevention or compensation of the surgical loss in healthy patients, because there have been few studies on the relationship between type of surgery or bleeding and iron loss. Finally, we did not measure the long-term postoperative changes in hemoglobin, iron, and ferritin levels, such as those occurring over weeks to months. However, based on previously reported findings $[30,43]$, sufficient amounts of iron and ferritin in patients with IV iron therapy may play roles in restoring appropriate hemoglobin levels postoperatively. However, our study is the first to perform a non-inferiority comparison of the effect of a novel IV iron drug (ferric carboxymaltose) and conventional blood salvage therapy (autologous whole blood donation) on the postoperative hemoglobin level in robust young patients undergoing bimaxillary orthognathic surgery. Although previous studies suggested IV iron therapy ensured better oxygen-carrying capacity, those studies were limited by comparison to normal saline therapy as a control group.

\section{Conclusion}

Although the levels of hemoglobin, iron, and ferritin were better immediately before surgery in healthy patients who received preoperative IV iron therapy, this treatment did not seem to be effective for significantly raising hemoglobin levels or reducing the low hemoglobin levelbased requirement for allogeneic blood transfusion compared to AWBT after surgical hemorrhage and injury. However, as collection of autologous whole blood caused overt iron loss and anemia before surgery and intraoperative transfusion of the whole blood was unable to prevent the occurrence of persistent iron deficiency after surgery, IV iron therapy has potential benefits for iron homeostasis and subsequent erythropoiesis in healthy patients early after bimaxillary orthognathic surgery. Therefore, preoperative IV iron therapy alone may be equally effective in ensuring a sufficient hemoglobin level on POD 1 compared to therapy with intraoperative infusion of autologous whole blood harvested before surgery, but the non-inferiority results did not persist after POD 1. Appropriately powered randomized controlled trials examining the effects of IV iron with/without autologous whole blood and subsequent long-term outcome after bimaxillary orthognathic surgery are required.

\section{Supplementary Information}

The online version contains supplementary material available at https://doi. org/10.1186/s12903-020-01359-1.

Additional file 1. Consolidated Standards of Reporting Trials (CONSORT) guidelines.

Additional file 2. Summary of our bimaxillary orthognathic surgery protocol.

Additional file 3. Comparison of perioperative inflammatory and coagulation findings between the two groups.

\section{Abbreviations}

IV: Intravenous; POD: Postoperative day; ASA: American Society of Anesthesiologists; SBP: Systolic blood pressure; DBP: Diastolic blood pressure; HR: Heart rate; PRBC: Packed red blood cell; BMI: Body mass index; RBC: Red blood cell; INR: International normalized ratio; VAS: Visual analogue scale; IQR: Interquartile.

\section{Acknowledgements}

The authors wish to acknowledge the financial support of the Catholic Medical Center Research Foundation made in the program year of 2020.

\section{Authors' contributions}

M.S.C. and Y.E.M. designed the study, wrote the manuscript, and analyzed and interpreted the data. M.S.C., M.L., H.C., J.J., and Y.E.M. collected the data and provided critical comments. M.P. and Y.H.K. performed the statistical analyses. All authors revised the manuscript critically for important intellectual content. All authors read and approved the final manuscript.

\section{Funding}

The authors wish to acknowledge the financial support of the Catholic Medical Center Research Foundation made in the program year of 2020.

\section{Availability of data and materials}

The datasets used and/or analysed during this study are available from the corresponding author on reasonable request.

\section{Ethics approval and consent to participate}

This was a prospective, patient-randomized, noninferiority trial. The protocol was approved by the Institutional Review Board of Seoul St. Mary's Hospital Ethics Committee (Approval No. KC18MESI0583) on December 19, 2018. The study was performed in accordance with the principles of the Declaration of Helsinki. The study protocol was prospectively registered at a publicly accessible clinical registration site that is recognized by the International Committee of Medical Journal Editors (Clinical Research Information Service, Republic of Korea, approval number: KCT0003680) on March 27, 2019. Written informed consent was obtained from all patients at our hospital who were enrolled between March 2019 and May 2020. The study adhered to the Consolidated Standards of Reporting Trials (CONSORT) guidelines (Additional file 1) and a CONSORT flow chart is provided in Fig. 1. Additional file 2 presents a summary of our study protocol.

\section{Consent for publication}

Not applicable.

\section{Competing interests}

The authors have no conflicts of interest to declare.

\section{Author details}

${ }^{1}$ Department of Anesthesiology and Pain Medicine, Seoul St. Mary's Hospital, College of Medicine, The Catholic University of Korea, 222, Banpo-daero, Seocho-gu, Seoul 06591, Republic of Korea. ${ }^{2}$ Department of Oral and Maxillofacial Surgery, Seoul St. Mary's Hospital, College of Medicine, The Catholic University of Korea, Seoul, Republic of Korea. ${ }^{3}$ Department of Biostatistics, Clinical Research Coordinating Center, Catholic Medical Center, The Catholic University of Korea, Seoul, Republic of Korea. 
Received: 24 August 2020 Accepted: 9 December 2020

Published online: 07 January 2021

\section{References}

1. Moenning JE, Bussard DA, Lapp TH, Garrison BT. Average blood loss and the risk of requiring perioperative blood transfusion in 506 orthognathic surgical procedures. J Oral Maxillofac Surgery. 1995;53(8):880-3.

2. Neuwirth BR, White RP Jr, Collins ML, Phillips C. Recovery following orthognathic surgery and autologous blood transfusion. Int J Adult Orthodont Orthognathic Surg. 1992;7(4):221-8.

3. Marciani RD, Dickson LG. Autologous transfusion in orthognathic surgery. J Oral Maxillofac Surg. 1985;43(3):201-4.

4. Ervens J, Marks C, Hechler M, Plath T, Hansen D, Hoffmeister B. Effect of induced hypotensive anaesthesia vs isovolaemic haemodilution on blood loss and transfusion requirements in orthognathic surgery: a prospective, single-blinded, randomized, controlled clinical study. Int J Oral Maxillofac Surg. 2010;39(12):1168-74.

5. Newman ET, Watters TS, Lewis JS, Jennings JM, Wellman SS, Attarian DE, Grant SA, Green CL, Vail TP, Bolognesi MP. Impact of perioperative allogeneic and autologous blood transfusion on acute wound infection following total knee and total hip arthroplasty. J Bone Joint Surg Am. 2014:96(4):279-84

6. Avgerinos DV, DeBois W, Salemi A. Blood conservation strategies in cardiac surgery: more is better. Eur J Cardio-thoracic Surg. 2014;46(5):865-70.

7. Cable RG, Brambilla D, Glynn SA, Kleinman S, Mast AE, Spencer BR Stone M, Kiss JE. Effect of iron supplementation on iron stores and total body iron after whole blood donation. Transfusion. 2016;56(8):2005-12.

8. Kiss JE, Brambilla D, Glynn SA, Mast AE, Spencer BR, Stone M, Kleinman SH, Cable RG. Oral iron supplementation after blood donation: a randomized clinical trial. JAMA. 2015:313(6):575-83.

9. Kiss JE, Vassallo RR. How do we manage iron deficiency after blood donation? Br J Haematol. 2018;181(5):590-603.

10. Piednoir P, Allou N, Driss F, Longrois D, Philip I, Beaumont C, Montravers $P$, Lasocki S. Preoperative iron deficiency increases transfusion requirements and fatigue in cardiac surgery patients: a prospective observational study. Eur J Anaesthesiol. 2011;28(11):796-801.

11. Toy P, Feiner J, Viele MK, Watson J, Yeap H, Weiskopf RB. Fatigue during acute isovolemic anemiain healthy, resting humans. Transfusion. 2000:40(4):457-60.

12. Yoon HM, Kim YW, Nam BH, Reim D, Eom BW, Park JY, Ryu KW. Intravenous iron supplementation may be superior to observation in acute isovolemic anemia after gastrectomy for cancer. World J Gastroenterol. 2014:20(7):1852-7.

13. Keating GM. Ferric carboxymaltose: a review of its use in iron deficiency. Drugs. 2015:75(1):101-27.

14. Serrano-Trenas JA, Ugalde PF, Cabello LM, Chofles LC, Lazaro PS, Benitez PC. Role of perioperative intravenous iron therapy in elderly hip fracture patients: a single-center randomized controlled trial. Transfusion. 2011;51(1):97-104

15. Anker SD, Comin Colet J, Filippatos G, Willenheimer R, Dickstein K Drexler H, Lüscher TF, Bart B, Banasiak W, Niegowska J, et al. Ferric carboxymaltose in patients with heart failure and iron deficiency. $\mathrm{N}$ Engl J Med. 2009;361(25):2436-48.

16. Usmanov RI, Zueva EB, Silverberg DS, Shaked M. Intravenous iron without erythropoietin for the treatment of iron deficiency anemia in patients with moderate to severe congestive heart failure and chronic kidney insufficiency. J Nephrol. 2008;21(2):236-42.

17. Munoz M, Breymann C, Garcia-Erce JA, Gomez-Ramirez S, Comin J, Bisbe E. Efficacy and safety of intravenous iron therapy as an alternative/adjunct to allogeneic blood transfusion. Vox Sang. 2008;94(3):172-83.

18. Mayhew D, Mendonca $V$, Murthy BVS. A review of ASA physical status-historical perspectives and modern developments. Anaesthesia. 2019;74(3):373-9.

19. Practice guidelines for perioperative blood management. an updated report by the American Society of Anesthesiologists Task Force on Perioperative Blood Management*. Anesthesiology. 2015;122(2):241-75.
20. Zhou J. A review of the application of autologous blood transfusion. Braz J Med Biol Res. 2016;49(9):e5493.

21. Storch EK, Custer BS, Jacobs MR, Menitove JE, Mintz PD. Review of current transfusion therapy and blood banking practices. Blood Rev. 2019:38:100593.

22. Zhou J, Chen Z, Jin J, Zhang QL. A study of preoperative autologous blood donation timing. Indian J Hematol Blood Transf. 2018;34(1):138-42.

23. Park HJ, Park JU, Yoo W, Moon YE. Analgesic effects of nefopam in patients undergoing bimaxillary osteotomy: a double-blind, randomized, placebo-controlled study. J Cranio-Maxillo-Facial Surg. 2016:44(2):210-4.

24. Clavien PA, Barkun J, de Oliveira ML, Vauthey JN, Dindo D, Schulick RD, de Santibañes E, Pekolj J, Slankamenac K, Bassi C, et al. The ClavienDindo classification of surgical complications: five-year experience. Ann Surg. 2009;250(2):187-96.

25. Piaggio G, Elbourne DR, Pocock SJ, Evans SJ, Altman DG. Reporting of noninferiority and equivalence randomized trials: extension of the CONSORT 2010 statement. JAMA. 2012;308(24):2594-604.

26. Bonar RA, Lippi G, Favaloro EJ. Overview of hemostasis and thrombosis and contribution of laboratory testing to diagnosis and management of hemostasis and thrombosis disorders. Methods Mol Biol (Clifton). 2017;1646:3-27.

27. Bolger AP, Bartlett FR, Penston HS, O'Leary J, Pollock N, Kaprielian $\mathrm{R}$, Chapman CM. Intravenous iron alone for the treatment of anemia in patients with chronic heart failure. J Am Coll Cardiol. 2006:48(6):1225-7.

28. Hogan M, Klein AA, Richards T. The impact of anaemia and intravenous iron replacement therapy on outcomes in cardiac surgery. Eur J Cardiothoracic Surg. 2015;47(2):218-26.

29. Elhenawy AM, Meyer SR, Bagshaw SM, MacArthur RG, Carroll LJ. Role of preoperative intravenous iron therapy to correct anemia before major surgery: study protocol for systematic review and meta-analysis. Syst Rev. 2015;4:29.

30. Kim YW, Bae JM, Park YK, Yang HK, Yu W, Yook JH, Noh SH, Han M, Ryu $\mathrm{KW}$, Sohn TS, et al. Effect of intravenous ferric carboxymaltose on hemoglobin response among patients with acute isovolemic anemia following gastrectomy: The FAIRY randomized clinical trial. JAMA. 2017;317(20):2097-104.

31. van Iperen CE, Gaillard CA, Kraaijenhagen RJ, Braam BG, Marx JJ, van de Wiel A. Response of erythropoiesis and iron metabolism to recombinant human erythropoietin in intensive care unit patients. Crit Care Med. 2000;28(8):2773-8.

32. Roger SD, Gaillard CA, Bock AH, Carrera F, Eckardt KU, Van Wyck DB, Cronin M, Meier Y, Larroque S, Macdougall IC. Safety of intravenous ferric carboxymaltose versus oral iron in patients with nondialysisdependent CKD: an analysis of the 1-year FIND-CKD trial. Nephrol Dialysis Transpl. 2017;32(9):1530-9

33. Wolf M, Koch TA, Bregman DB. Effects of iron deficiency anemia and its treatment on fibroblast growth factor 23 and phosphate homeostasis in women. J Bone Min Res. 2013;28(8):1793-803.

34. Cada DJ, Levien TL, Baker DE. Ferric carboxymaltose. Hosp Pharm. 2014:49(1):52-9.

35. Oh AY, Seo KS, Lee GE, Kim HJ. Effect of preoperative autologous blood donation on patients undergoing bimaxillary orthognathic surgery: a retrospective analysis. Int J Oral Maxillofac Surg. 2016;45(4):486-9.

36. Lahsaee SM, Ghaffaripour S, Hejr H. The effect of routine maintenance intravenous therapy on hemoglobin concentration and hematocrit during anesthesia in adults. Bull Emerg Trauma. 2013;1(3):102-7.

37. Kretschmer W, Koster U, Dietz K, Zoder W, Wangerin K. Factors for intraoperative blood loss in bimaxillary osteotomies. J Oral Maxillofac Surg. 2008;66(7):1399-403.

38. Gell DA. Structure and function of haemoglobins. Blood Cells Mol Dis. 2018;70:13-42

39. Long MY, Liu ZH, Zhu JG. Comparative analysis of autologous blood transfusion and allogeneic blood transfusion in surgical patients. Int J Clin Exp Med. 2014;7(9):2889-94.

40. Jakovina Blazekovic S, Bicanic G, Hrabac P, Tripkovic B, Delimar D. Pre-operative autologous blood donation versus no blood donation in total knee arthroplasty: a prospective randomised trial. Int Orthop. 2014:38(2):341-6. 
41. Spinella PC, Cap AP. Whole blood: back to the future. Curr Opin Hematol. 2016;23(6):536-42.

42. Walunj A, Babb A, Sharpe R. Autologous blood transfusion. Continuing Educ Anaesth Crit Care Pain. 2006;6(5):192-6.

43. Lee B, Kim EJ, Song J, Jung YS, Koo BN. A randomised trial evaluating the effect of intraoperative iron administration. Sci Rep. 2020;10(1):15853.

\section{Publisher's Note}

Springer Nature remains neutral with regard to jurisdictional claims in published maps and institutional affiliations.
Ready to submit your research? Choose BMC and benefit from:

- fast, convenient online submission

- thorough peer review by experienced researchers in your field

- rapid publication on acceptance

- support for research data, including large and complex data types

- gold Open Access which fosters wider collaboration and increased citations

- maximum visibility for your research: over $100 \mathrm{M}$ website views per year

At BMC, research is always in progress.

Learn more biomedcentral.com/submissions 